\title{
Hepatitis E virus infection in Brazil: results of laboratory-based surveillance from 1998 to 2013
}

\author{
Ana Maria Passos-Castilho ${ }^{[1]}$, Anne de Sena ${ }^{[1],[2],}$ \\ Mônica Renata Reinaldo ${ }^{[1],[2]}$ \\ and Celso Francisco Hernandes Granato ${ }^{[1],[2]}$
}

[1]. Departamento de Medicina, Universidade Federal de São Paulo, São Paulo, Brasil. [2]. Fleury Medicina e Saúde, Grupo Fleury S/A, São Paulo, Brasil.

\begin{abstract}
Introduction: Data on hepatitis E virus (HEV) in Brazil are limited. We analyzed 15 years of HEV surveillance data in a major clinical laboratory in São Paulo, Brazil. Methods: The seroprevalence of HEV of 2,271 patients subjected to anti-HEV tests from 1998 to 2013 were analyzed. Results: HEV seroprevalence was $2.1 \%$, and the anti-HEV IgM positivity rate was $4.9 \%$. Six hepatitis E patients were identified. Conclusions: HEV seroprevalence and detection rates appear to have increased in recent years. Hepatitis E should be investigated further and included in the differential diagnosis of hepatitis in Brazil.
\end{abstract}

Keywords: Hepatitis E virus. Epidemiology. Seroprevalence.

Hepatitis E occurs as both large epidemics and sporadic cases in endemic areas, including genotypes 1, 2, and 4 in Asia and Africa, Mexico and Africa, and Asia, respectively. Meanwhile, sporadic cases of genotype 3 occur in Europe, Japan, and the Americas. Genotypes 1 and 2 are restricted to primates and are transmitted predominantly via the fecal-oral route. Genotypes 3 and 4 infect numerous mammalian species and can be transmitted via the ingestion of raw or undercooked meat from infected animals ${ }^{(1)}$.

Data on hepatitis E virus (HEV) seroprevalence in Brazil are limited. Although this region is classified as moderately endemic for $\mathrm{HEV}$, most available studies are outdated and cannot be compared properly because of their small sample sizes and/ or diverse methodology $\mathrm{y}^{(2)}$. Moreover, HEV is not routinely investigated in Brazil, even in cases of unexplained liver enzyme elevation or acute hepatitis, and only a few laboratories perform anti-HEV tests. Therefore, the occurrence and characteristics of hepatitis E in Brazil are poorly understood. Thus, the present study reports 15 years of HEV surveillance data, including seroprevalence, from a major clinical laboratory in Brazil.

We retrospectively analyzed all laboratory records of antiHEV tests performed between January 1998 and December 2013 in a major clinical laboratory in São Paulo, Brazil that covers an area extending from Southern to Northeastern Brazil.

Corresponding author: $\mathrm{Dr}^{\mathrm{a}}$ Ana Maria Passos-Castilho. Rua Pedro de Toledo 781, 04039-032 São Paulo, Brasil.

Phone: 5511 5081-5394

e-mail: anampassos@gmail.com

Received 30 January 2015

Accepted 17 March 2015
The samples originated from patients clinically suspected of being HEV carriers at clinics or hospitals. The study protocol was approved by the appropriate institutional ethics committee (approval numbers: 162/09 and 86730/14).

All serum samples were shipped to the Quest Diagnostics Nichols Institute (San Juan Capistrano, CA, USA) where antiHEV immunoglobulin G (IgG) and immunoglobulin M (IgM) antibodies were tested by enzyme-linked immunosorbent assay (ELISA). Information on age, sex, origin, comorbidities, transplants, and hepatic enzyme and bilirubin test results was collected from medical records.

Descriptive statistics were used to analyze demographic, clinical, and laboratory characteristics as well as anti-HEV seroprevalence. Continuous variables are presented as percentages, medians and ranges, and means and standard deviations (SDs) where appropriate. Categorical variables were analyzed by Pearson's $\chi^{2}$ test. Linear regression analysis was used to evaluate the trends of anti-HEV positivity with respect to year and age. All data were analyzed by Statistical Package for the Social Sciences (SPSS) version 11.0 (SPSS Inc., Chicago, IL, USA). All reported values are two-tailed, and the level of significance was set at $\mathrm{p}<0.05$.

The epidemiological and laboratory data with respect to anti-HEV IgG status are shown in Table 1. Between January 1998 and December 2013, 2,271 patients underwent anti-HEV IgG tests. The median age of patients was 37 years (range: $0-94$ years old, mean \pm SD: $37.8 \pm 16.0$ years). Moreover, $50.5 \%$ were female.

The overall anti-HEV IgG positivity rate was $2.1 \%$ $(47 / 2,271)$, ranging from $0 \%(0 / 183)$ to $8.6 \%(12 / 139)$ annually. Anti-HEV IgG positivity exhibited a significant linear trend 
with year $(\mathrm{p}=0.010)$. The highest frequencies were observed from 2011 to $2013: 5.9 \%(2 / 34), 8.6 \%(12 / 139)$, and $6.1 \%(9 / 148)$, respectively. HEV seropositivity was not linearly associated with age; however, it was significantly associated with age group, with the highest frequencies in persons older than 40 years (median age of $47 \mathrm{HEV}$ seropositive patients: 46 years, range: 10-94 years; median age of seronegative patients: 36 years, range: $0-91$ years; $\mathrm{p}<0.0001)$. There were no differences in HEV seropositivity with respect to sex, hepatic enzymes, or bilirubin.

The anti-HEV IgM test became available in January 2006, and 552 tests were performed from 2006 to December 2013. The anti-HEV IgM positivity rate was $4.9 \%$ (27/552), ranging from $0 \%(0 / 47)$ to $8.8 \%(3 / 34)$ annually. IgM positivity exhibited a linear trend over time $(\mathrm{p}=0.016)$; the highest frequencies were observed from 2011 to 2013: 8.8\% (3/34), 5.8\% (8/139), and $7.4 \%$ (11/148), respectively. Although the IgM positivity rate did not exhibit a linear trend with age, it was significantly associated with age group $(p=0.041)$; the highest IgM frequencies were observed in people aged $10-19$ years $(12.5 \% ; 7 / 56)$ and $0-9$ years $(5.3 \% ; 2 / 38)$ (median age of $27 \mathrm{HEV} \mathrm{IgM-positive} \mathrm{patients:}$ 36 years, range: $1-59$ years; median age of IgM-negative patients: 36 years, range: $0-94$ years. Anti-HEV IgM positivity was not associated with sex, hepatic enzymes, or bilirubin.

Of the 47 anti-HEV IgG-positive patients, 28 (59.6\%) were evaluated from 2006 to 2013 and therefore also have anti-HEV IgM results. Six (1.1\%) patients exhibited both $\operatorname{IgM}$ and $\operatorname{IgG}$ positivity and were considered acute hepatitis E cases (Table 2). Because of the retrospective nature of this study, we could only further investigate case no. 2, in which HEV ribonucleic acid (RNA) was detected (genotype 3b, Brazil h4, GenBank accession number: KF152884) with a viral load of $4.5 \log _{10}$ copies $/ \mathrm{mL}$. Examination of viral RNA extracted from paraffin-embedded formalin-fixed liver tissue (RNeasy FFPE kit; Qiagen, Germany) from 3 years prior showed the presence of HEV sharing $>99 \%$ homology with the sequence found in the serum sample from 2013, thus indicating chronic hepatitis E infection (KM502569). The patient was treated with ribavirin for 10 months, and her HEV RNA load became undetectable ( $<100$ copies/L) in August $2013^{(3)}$.

Studies conducted on blood donors in Brazil from 1997 to 2006 report the prevalence of anti-HEV IgG to be
TABLE 1 - Epidemiological and laboratory data of samples according to anti-HEV IgG status in Brazil (1998-2013).

\begin{tabular}{|c|c|c|c|c|c|}
\hline \multirow[t]{2}{*}{ Variable } & \multicolumn{2}{|c|}{$\begin{array}{l}\text { Anti-HEV } \\
\text { IgG positive }\end{array}$} & \multirow[b]{2}{*}{$\mathbf{p}$} & \multicolumn{2}{|c|}{$\begin{array}{c}\text { Anti-HEV } \\
\text { IgG negative }\end{array}$} \\
\hline & n & $\%$ & & n & $\%$ \\
\hline
\end{tabular}

Age group (years)

\begin{tabular}{lccccc}
$0-19$ & 3 & 1.1 & $0.008^{*}$ & 265 & 98.9 \\
$20-39$ & 12 & 1.2 & & 966 & 98.8 \\
$40-59$ & 26 & 3.4 & & 736 & 96.6 \\
$60-94$ & 6 & 2.9 & & 200 & 97.1 \\
\hline
\end{tabular}

Sex

\begin{tabular}{llllll} 
female & 20 & 1.7 & 0.273 & 1126 & 98.3 \\
male & 27 & 2.4 & & 1097 & 97.6 \\
\hline
\end{tabular}

AST

\begin{tabular}{llllll} 
elevated & 4 & 1.7 & 0.877 & 229 & 98.3 \\
normal & 8 & 1.6 & & 504 & 98.4 \\
\hline
\end{tabular}

ALT

\begin{tabular}{llllll} 
elevated & 8 & 2.1 & 0.441 & 378 & 97.9 \\
normal & 6 & 1.4 & & 430 & 98.6 \\
\hline
\end{tabular}

\section{GGT}

\begin{tabular}{llllll} 
elevated & 4 & 1.7 & 0.714 & 227 & 98.3 \\
normal & 6 & 1.4 & & 432 & 98.6 \\
\hline
\end{tabular}

Bilirubin

$\begin{array}{lccccc}\text { elevated } & 2 & 2.0 & 0.916 & 98 & 98.0 \\ \text { normal } & 7 & 2.2 & & 315 & 97.8\end{array}$

HEV: hepatitis E virus; IgG: immunoglobulin G; AST: aspartate aminotransferase; ALT: alanine aminotransferase; GGT: gamma-glutamyl transpeptidase; Reference values: AST $\leq 31 \mathrm{U} / \mathrm{L}$ in females and $\leq 37 \mathrm{U} / \mathrm{L}$ in males; ALT $\leq 31 \mathrm{U} / \mathrm{L}$ in females and $\leq 41 \mathrm{U} / \mathrm{L}$ in males; GGT 8 to $41 \mathrm{U} / \mathrm{L}$ in females and 12 to $73 \mathrm{IU} / \mathrm{L}$ in males; Bilirubin 0.2 to $1.1 \mathrm{mg} / \mathrm{dL} .{ }^{*} \mathrm{p}<0.05$ with Pearson's $\chi^{2}$ test.

TABLE 2 - Clinical and laboratory data of patients with hepatitis E in Brazil (1998-2013).

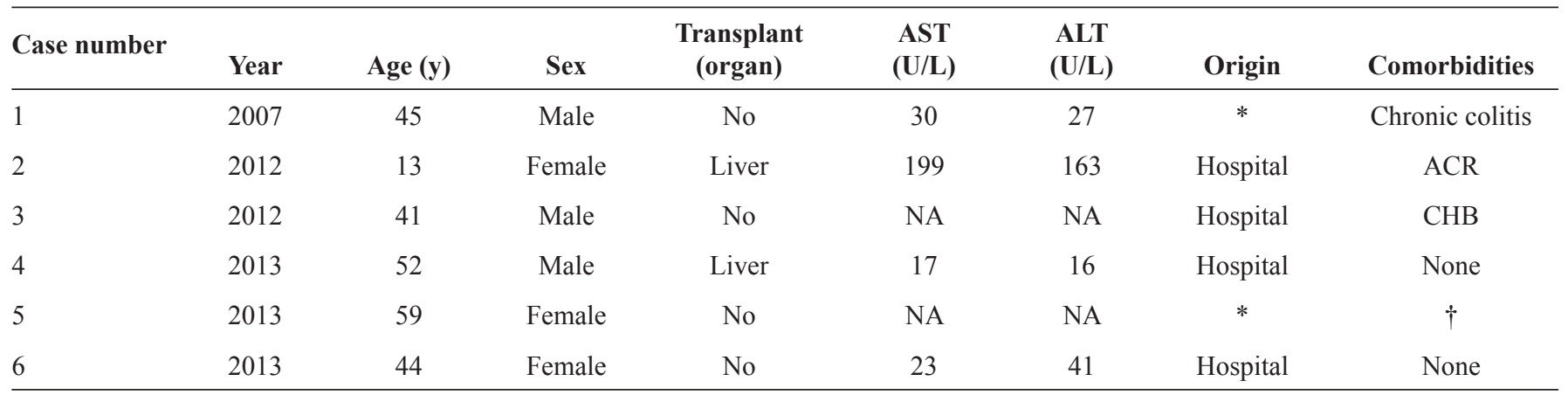

AST: aspartate aminotransferase; ALT: alanine aminotransferase; ACR: acute cellular rejection; NA: not available; CHB: chronic hepatitis B. *Samples sent from other laboratories for confirmation. $†$ This patient had positive anti-HEV IgM and IgG results in October 2013 and again in February 2014. 
$2.0-4.3 \% \%^{(4)}$. A 2002 study on laboratory patients reports a $2.4 \%$ seroprevalence ${ }^{(5)}$. In the present study, the anti-HEV IgG positivity was ranged 0-3.6\% from 1998 to 2006, reaching 8.6\% in 2012.

Solid organ transplant recipients are more susceptible to hepatitis $\mathrm{E}$ infection and even chronic hepatitis $\mathrm{E}^{(6)}$. Our previous study of 192 renal transplant patients in São Paulo, Brazil identified $20(10 \%)$ patients positive for HEV RNA and 28 (15\%) positive for anti-HEV IgG antibodies ${ }^{(7)}$. The HEV strains were genotype 3; further investigation of 3 patients suggested chronic hepatitis E, although the retrospective study design precluded follow-up ${ }^{(8)}$.

It should be noted that the present data did not come from an established systematic program of epidemiologic surveillance in Brazil. Therefore, the actual prevalence of hepatitis E may differ. Hence, future epidemiological studies must include the general population to accurately characterize HEV in Brazil.

In summary, the present study provides valuable insights into the detection and seroprevalence of hepatitis E in Brazil. HEV seroprevalence and detection rates appear to have increased in recent years. Cases have occurred in both immunocompetent and immunocompromised patients. Therefore, hepatitis E should be investigated further and included in the differential diagnosis of suspected hepatitis in Brazil.

\section{CONFLICT OF INTEREST}

The authors declare that there is no conflict of interest.

\section{FINANCIAL SUPPORT}

This work was supported by the Fundação de Amparo à Pesquisa do Estado de São Paulo grants no. 2012/22925-3 and 2013/03701-0.

\section{REFERENCES}

1. Kamar N, Dalton HR, Abravanel F, Izopet J. Hepatitis E virus infection. Clin Microbiol Rev 2014; 27:116-138.

2. Echevarría JM, González JE, Lewis-Ximenez LL, Dos Santos DR, Munné MS, Pinto MA, et al. Hepatitis E virus infection in Latin America: a review. J Med Virol 2013; 85:1037-1045.

3. Passos-Castilho AM, Porta G, Miura IK, Pugliesi RPS, Dansei, VLB, Porta A, et al. Chronic hepatitis $\mathrm{E}$ virus infection in a pediatric female liver transplant recipient. J Clin Microbiol 2014; 52:4425-4427.

4. Carrilho FJ, Mendes Clemente C, Silva LC. Epidemiology of hepatitis A and E virus infection in Brazil. Gastroenterol Hepatol 2005; 28:118-125.

5. Santos DC, Souto FJ, Lopes dos Santos DR, Vitral CL, Gaspar AM. Seroepidemiological markers of enterically transmitted viral hepatitis $\mathrm{A}$ and $\mathrm{E}$ in individuals living in a community located in the North Area of Rio de Janeiro, RJ, Brazil. Mem Inst Oswaldo Cruz 2002; 97:637-640.

6. Kamar N, Garrouste C, Haagsma EB, Garrigue V, Pischke S, Chauvet $\mathrm{C}$, et al. Factors associated with chronic hepatitis in patients with hepatitis $\mathrm{E}$ virus infection who have received solid organ transplants. Gastroenterology 2011; 140:1481-1489.

7. Hering T, Passos AM, Perez RM, Bilar J, Fragano D, Granato C, et al. Past and current hepatitis E virus infection in renal transplant patients. J Med Virol 2014; 86:948-953.

8. Passos AM, Heringer TP, Medina-Pestana JO, Ferraz ML, Granato $\mathrm{CF}$. First report and molecular characterization of hepatitis $\mathrm{E}$ virus infection in renal transplant recipients in Brazil. J Med Virol 2013; 85:615-619. 